\title{
Structural, optical and electrical properties of spray pyrolytically deposited thin films of $\mathrm{CuInS}_{2}$
}

\author{
Y D TEMBHURKAR and J P HIRDE \\ Department of Physics, Institute of Science, Nagpur 440001, (M.S.), India \\ MS received 30 May 1992: revised 22 April 1993
}

\begin{abstract}
CuInS}_{2}$ is a promising chalcopyrite semiconducting material for solar cell fabrication. Using aqueous solutions of cupric chloride, indium trichloride and thiourea, we deposited thin $\mathrm{CuInS}_{2}$ films on glass at $350^{\circ} \mathrm{C}$ and studied their structural, optical and electrical properties. From the XRD pattern the chalcopyrite structure of these films was confirmed. The films were polycrystalline. The grain size estimated from scanning electron micrographs was found to be of the order of $1 \mu \mathrm{m}$. Resistivity of the film was measured for temperatures ranging from 77 to $473 \mathrm{~K}$. Band gap values were determined from optical transmission data. Hall mobility and carrier concentration at room temperature were calculated using Van der Pauw-Hall method.
\end{abstract}

Keywords. $\mathrm{CuInS}_{2}$ thin films; chalcopyrite semiconductors.

\section{Introduction}

$\mathrm{CuInS}_{2}$ is a member of the I-III-VI family of chalcopyrite semiconductors with a band gap of $1.55 \mathrm{eV}$ and hence has been predicted to yield photocells of efficiency (Meese et al 1975) between $27 \%$ and $32 \%$. CuInS 2 photocells have shown $15 \%$ efficiency (Tell and Thiel 1979). Solar cells of $\mathrm{CuInS}_{2}$ thin film homo-junction produced by vacuum evaporation with efficiency up to $3.62 \%$ have been demonstrated by Kazmerski and Sanborn (1977). Many research groups have investigated the properties of this compound in the form of a single crystal. There is a need for systematic evaluation of the variables associated with the production of $\mathrm{CuInS}_{2}$ thin films so that electrical, optical and structural characteristics can be easily understood and controlled for device applications.

Different techniques of thin film deposition such as double-source method (Kazmerski et al 1975), flash evaporation (Hwang et al 1980a; Neumann et al 1981), r.f. sputtering (Hwang et al 1980c) and chemical vapour technique (Grindle et al 1979; Hwang et al $1980 \mathrm{~b}$ ) have been used and structural, optical and electrical properties of the thin films studied. Hiroyoshi and Kazuo (1984) used spray pyrolysis for depositing $\mathrm{CuInS}_{2}$ films and studied structural, optical and electrical properties above room temperature, while Rajaram et al (1983) studied the conductivity of spray pyrolytically deposited films of $\mathrm{CuInS}_{2}$ at room temperature.

The study of electrical properties at low temperatures gives information about the various mechanisms responsible for conduction in thin films. We have chosen the economical and convenient method of chemical spray pyrolysis for deposition of thin $\mathrm{CuInS}_{2}$ films and studied structural, optical and electrical properties of as-deposited films up to liquid nitrogen temperatures. Thickness of the films was measured by using a Michelson interferometer. The grain size was determined by SEM. The absorption edge analysis was carried out using transmittance vs wavelength data on a Hitachi spectrophotometer (model 330 UV-VIS-NIR). Hall mobility and carrier 
concentration at room temperature were determined by using Van der Pauw-Hall method. The conductivity type of the film was determined by hot-probe method.

\section{Film preparation}

Aqueous solutions of cupric chloride $\left(\mathrm{CuCl}_{2} \cdot 2 \mathrm{H}_{2} \mathrm{O}\right)$, indium trichloride $\left(\mathrm{InCl}_{3}\right)$ and thiourea $\left(\mathrm{H}_{2} \mathrm{NCSNH}_{2}\right)$ were used to prepare the films on hot glass substrates. Stock solutions of $0.02 \mathrm{M}$ of each of the above compounds was prepared in double distilled water. The chemicals used were of AR grade. Prior to use in deposition, the molarity of each solution was first reduced to $0.003 \mathrm{M}$ and then the solutions were mixed together in the ratio $1: 1: 3 \cdot 2$ by volume. Excess sulphur is necessary to obtain $\mathrm{CuInS}_{2}$ films. Deposited films show sulphur deficiency if the ratio of the solutions is $1: 1: 2$. Excess sulphur (in the form of thiourea) is used in order to remove this deficiency (Rajaram et al 1983). Biological glass slides (1.30 mm thick), were used as substrates. The temperature of the substrate, measured by a pre-calibrated thermocouple was maintained at $350^{\circ} \mathrm{C}$, which was the most suitable for the production of $\mathrm{CuInS}_{2}$ thin films. The solution mix was sprayed at $12 \mathrm{~kg} / \mathrm{cm}^{2}$ pressure. The distance between the sprayer nozzle and substrate was $30 \mathrm{~cm}$. The rate of flow was maintained at $3.5 \mathrm{ml} / \mathrm{min}$. The glass sprayer was mechanically moved to and fro during spraying to avoid formation of droplets on the hot substrate and to ensure instant evaporation.

\section{X-ray study}

Figure 1 shows the X-ray diffraction pattern for as-grown films of $\mathrm{CuInS}_{2} . \mathrm{Cu} \mathrm{K}_{\alpha}$ radiation with wavelength of $1.542 \AA$ was used. A pronounced diffraction peak corresponding to the 112 plane indicates preferred orientation as the direction of the 112 plane is least energy oriented for tetragonal systems. The other prominent peaks, corresponding to the $200,211,220,204,312,400$ and 424 planes, are also present. The positions of the peaks $112,220,200,116 / 312$ tally with those of the diffraction peaks obtained by Samann et al (1986) for r.f. sputtered films of $\mathrm{CuInS}_{2}$ and those obtained by Hiroyoshi and Kazuo (1984) for spray pyrolytically deposited films. However, the intensity order in our XRD pattern is slightly different. The above four

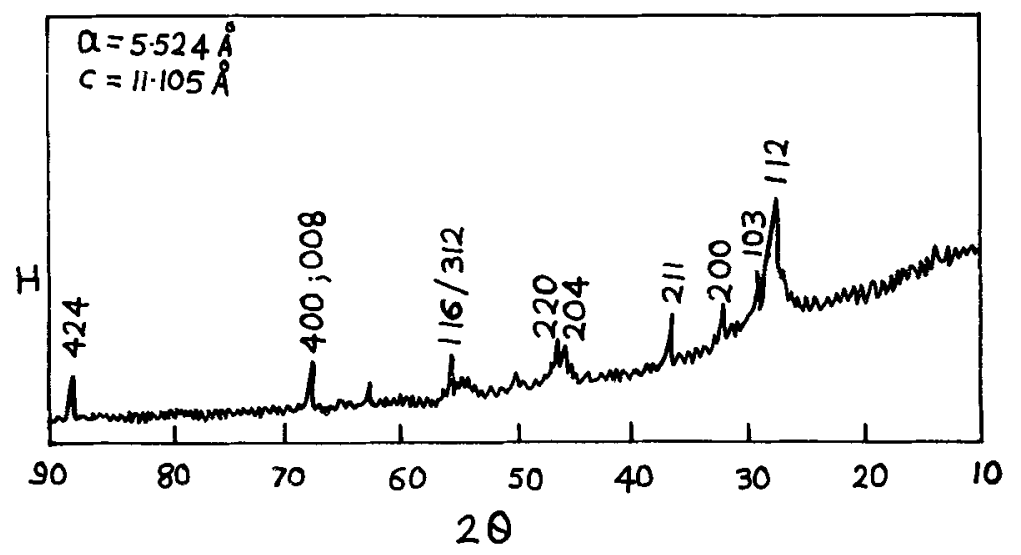

Figure 1. X-ray diffraction spectrum of as-deposited $\mathrm{CuInS}_{2}$ thin films on glass substrate. 


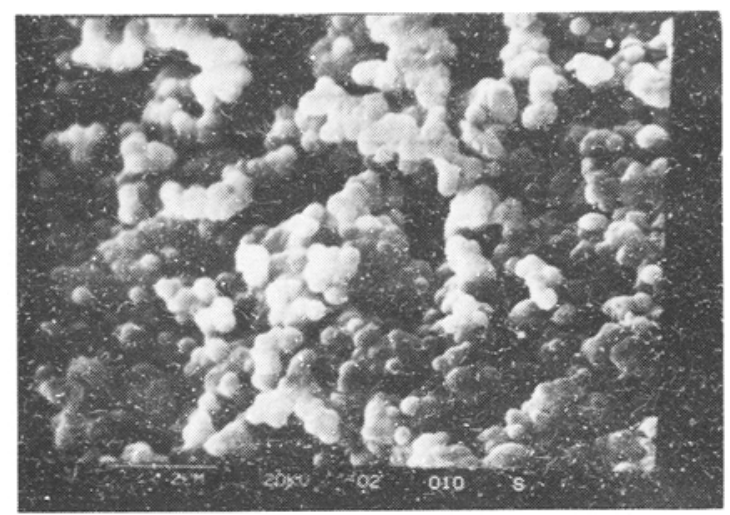

Figure 2. Scanning electron micrograph of the as-deposited thin films of CuInS $\mathrm{I}_{2}$ on glass substrate.

peaks are attributed to chalcopyrite phase of $\mathrm{CuInS}_{2}$ (Hiroyoshi and Kazuo 1984; Samann et al 1986). The positions of the other peaks obtained in our XRD pattern tally with ASTM data for tetragonal phase of $\mathrm{CuInS}_{2}$. The lattice parameters $a$ and $c$ calculated from the above diffraction peaks are $5.524 \AA$ and $11 \cdot 104 \AA$ respectively. The standard values of $a$ and $c$ for single crystals (ASTM No. 27-159) are 5.523 $\AA$ and $11 \cdot 141 \AA$ respectively. The values for our sprayed films therefore differ from the standard values by $0.001 \mathrm{~A}$ and $0.036 \AA$ respectively. The value of tetragonal distortion $(\Delta=2-c / a)$ was found to be negative, and equal to -0.01031 , indicating built-in dilation $(c>2 a)$ rather than compression. In general in I-III-VI ${ }_{2}$ compounds it is observed that $c<2 a$, which means compression (Shay and Wernick 1975).

Figure 2 shows the scanning electron micrograph of the as-deposited thin film of CuInS ${ }_{2}$. The grain size varies from $0.5 \mu \mathrm{m}$ to $1.0 \mu \mathrm{m}$.

\section{Optical study}

The optical transmission $(T)$ of the film was measured at room temperature using a Hitachi spectrophotometer (model 330 UV-VIS-NIR). Transmission was recorded for the wavelength range $400-1600 \mathrm{~nm}$ of the incident beam. Figure 3 shows transmission $(T)$ vs wavelength $(\hat{\lambda})$ for a film of thickness $0.15 \mu \mathrm{m}$.

The absorption coefficient $(\alpha)$ at various wavelengths for a sample of thickness $t$ is given by the relation

$$
x t=\ln \left(I_{0} . I\right)
$$

where $I_{0}$ and $I$ are the intensities of incident and transmitted radiation respectively. It is seen from figure 3 that interference effects can be neglected for films deposited on a thick non-absorbing substrate. The values of absorption coefficient $(\alpha)$ at various wavelengths were calculated from the transmission curve using relation (1) above.

Figure 4 shows the graph of $(x h)^{2}$ against $h{ }^{\prime}$, for $h v^{\prime} \leqslant 2 \cdot 0 \mathrm{eV}$, the region in which the graph is linear. This linear relation indicates that the direct allowed transition described by the relation

$$
\alpha=(A / h v)\left(h v-E_{\mathrm{g}}\right)^{1 / 2}
$$




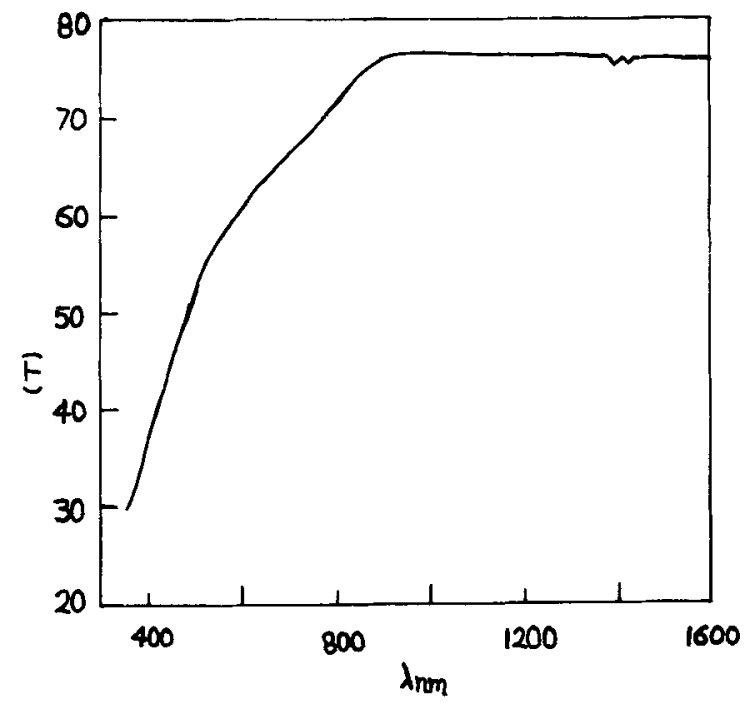

Figure 3. Transmission $T$ as a function of the wavelength $i$ of the as-deposited $\mathrm{CuInS}_{2}$ films on glass substrate (thickness of the film, $t=0.15 \mu \mathrm{m}$ ).

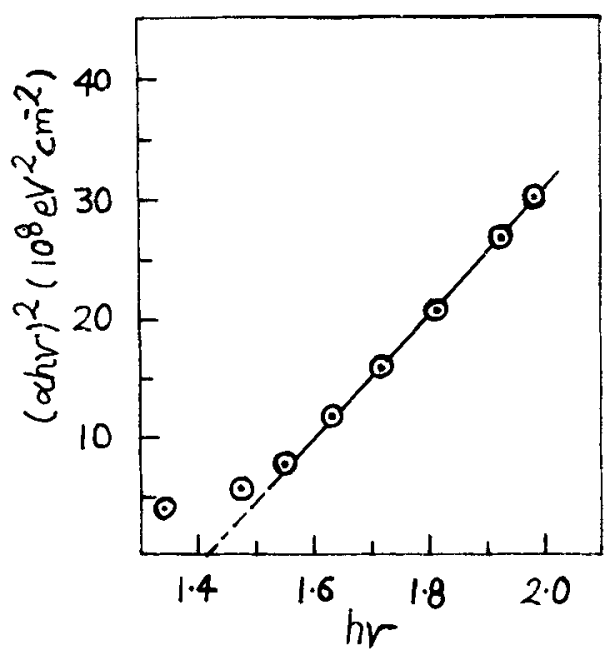

Figure 4. Plot of $(\alpha h v)^{2}$ against incident photon energy $(h v \leqslant 2 \cdot 0 \mathrm{eV})$.

is probably responsible for the absorption process. The band gap $\left(E_{\mathrm{g}}\right)$ determined from the intercept (by extrapolation) on the $h v$ axis was $1.43 \mathrm{eV}$. This result is in fairly good agreement with those of Rajaram et al (1983) and Hiroyoshi and Kazuo (1984), who reported band gap values of $1.44 \mathrm{eV}$ and $1.38-1.43 \mathrm{eV}$ respectively for spray pyrolytically deposited films. However, Pamplin and Fiegelson (1979) obtained a band gap value of $1.3 \mathrm{eV}$ for similar films. Neumann et al (1981) studied the optical properties of flash evaporated $\mathrm{CuInS}_{2}$ thin films and obtained an energy gap of $1.524 \mathrm{eV}$ at room temperature. The optical band gap value obtained by us $(1.43 \mathrm{eV})$ is smaller than that of a single crystal (Shay and Wernick 1975), which is $1.55 \mathrm{eV}$.

Using this value of band gap $\left(E_{\mathrm{g}}\right)$ and slope of the curve $(A)$, absorption coefficient 


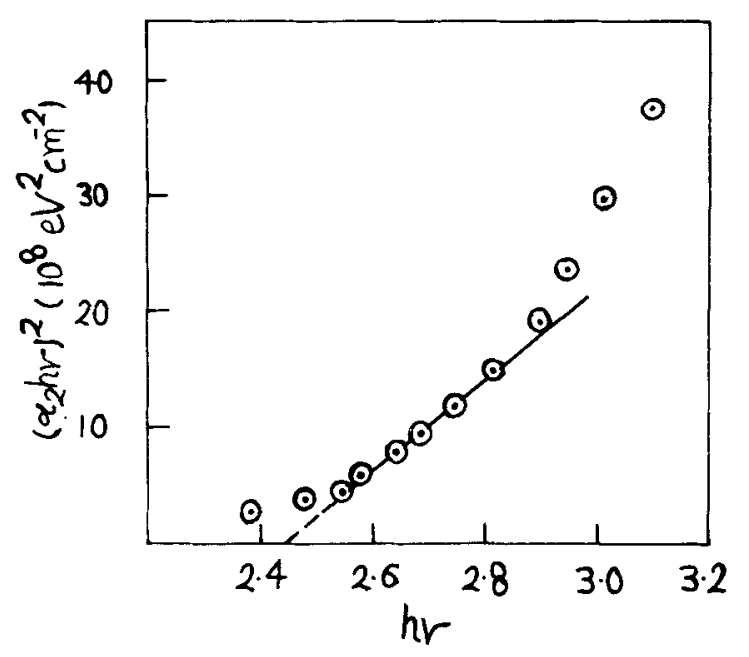

Figure 5. Plot of $\left(\alpha_{2} h v\right)^{2}$ against incident photon energy $(h v \geqslant 2 \cdot 0 \mathrm{eV})$.

was calculated for $h v \geqslant 2 \cdot 0 \mathrm{eV}$. We find that this calculated absorption coefficient is always less than the observed optical absorption coefficient for $h v \geqslant 2 \cdot 0 \mathrm{eV}$. This can only be explained if we assume the presence of an additional absorption process. We denote the absorption coefficient for $h v \leqslant 2.0 \mathrm{eV}$ by $\alpha_{1}$ and the absorption coefficient due to the additional process (for $h v \geqslant 2.0 \mathrm{eV}$ ) by $\alpha_{2} ; \alpha_{2}$ is given by the relation

$$
\alpha_{2}=\alpha_{\text {exp }}-\alpha_{\text {cal }} \text {. }
$$

Figure 5 shows $\left(\alpha_{2} h v\right)^{2}$ plotted against $h v$ for $h v \geqslant 2.0 \mathrm{eV}$. It is observed that the graph is a straight line up to $h v=2.82 \mathrm{eV}$, with an intercept of value $2.44 \mathrm{eV}$, indicating the presence of a second direct allowed transition. On the same lines if $\alpha_{3}$ is calculated for $h v \geqslant 2.82 \mathrm{eV}$, the graph of $\left(\alpha_{3} h v\right)^{2}$ vs $h v$ is a straight line and gives an intercept at $2 \cdot 71 \mathrm{eV}$. Neumann et al (1981) studied the optical properties of thin $\mathrm{CuInS}_{2}$ films produced by flash evaporation method. They found that the direct optical transitions corresponding to $1.524,2.81$ and $3.04 \mathrm{eV}$ were present. Our values are $1.43,2.44$ and $2.71 \mathrm{eV}$ and are smaller than the values obtained by Neumann et al (1981). According to Shay and Wernick (1975) all sulphides and selenides of $\mathrm{Cu}$ and $\mathrm{Ag}$ with $\mathrm{In}, \mathrm{Ga}$ or Al have direct energy gaps, probably due to transitions from copper-d-band to the lowest conduction band minimum.

\section{Electrical properties}

Conductivity of the film, as determined by the hot probe method, was of $p$-type. The resistivity was determined for two different ranges of temperature. Range (a) was from $300 \mathrm{~K}$ to $473 \mathrm{~K}$ and range (b) was from $77 \mathrm{~K}$ (liquid nitrogen temperature) to $273 \mathrm{~K}$. The resistivity in range (a) was measured at atmospheric pressure and in range (b) at $10^{-2}$ torr, for which a four-probe arrangement together with the sample film was enclosed in a specially prepared stainless steel container which was immersed in a liquid nitrogen bath.

Figure 6 shows the Arrhenius plot of conductivity vs inverse temperature of asdeposited film for the above temperature ranges. Three distinct regions of conductivity 


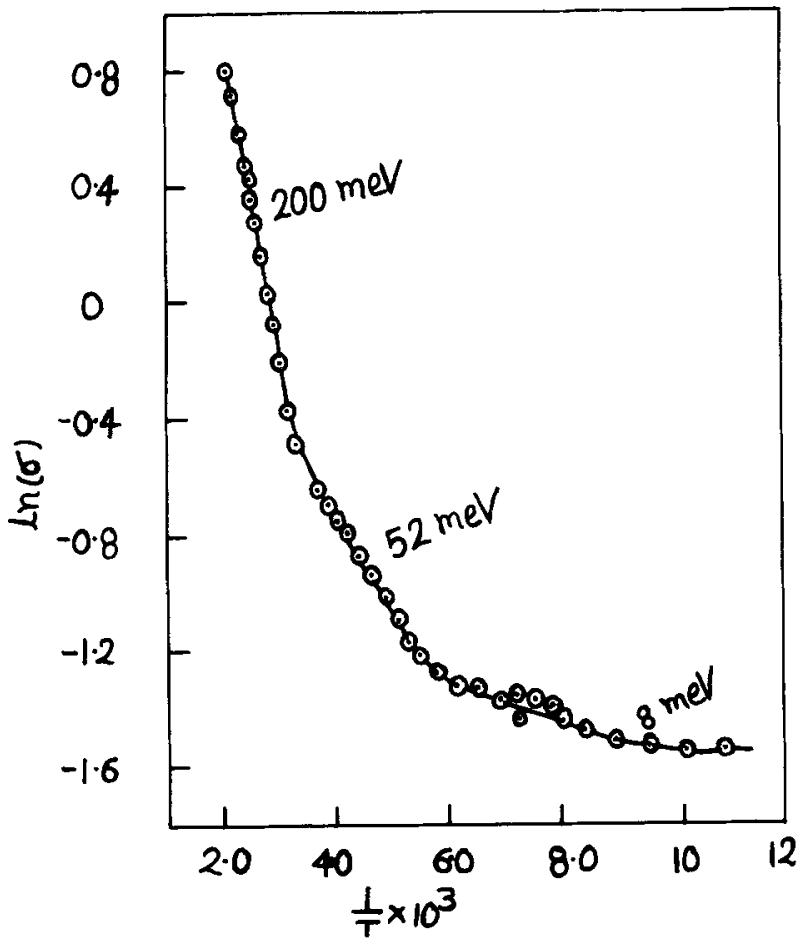

Figure 6. Arrhenius plot of conductivity of as-deposited CuInS ${ }_{2}$ thin films (temperature range $77 \mathrm{~K}$ to $473 \mathrm{~K}$ ).

are seen. Activation energies calculated for these three regions are $200 \mathrm{meV}, 52 \mathrm{meV}$ and $8 \mathrm{meV}$, for the temperature ranges $300-473 \mathrm{~K}, 160-250 \mathrm{~K}$ and $90-125 \mathrm{~K}$ respectively.

To study the conduction mechanism and the defect states one has to determine the resistivity in the region of very low temperature. As the temperature is lowered, the deeper levels can be progressively frozen out (Tuttle et al 1988). The Arrhenius plot can yield the different levels which are responsible for the different donor, acceptor mechanisms. Change in the carrier mechanism is indicated by change in the slope of the curve. As the films are not intentionally doped, intrinsic defects are expected to be present.

The activation energy of $200 \mathrm{meV}$ obtained in our experiment may be due to deep acceptor level. The activation energy obtained by Hiroyoshi and Kazuo (1984) for this range of temperature was $310 \mathrm{meV}$ for spray pyrolytically deposited $\mathrm{CuInS}_{2}$ films, annealed for $2 \mathrm{~h}$ at $500^{\circ} \mathrm{C}$ in vacuum. They have reported an increase in the height of the peak at an angle of $27.9^{\circ}$ which indicates that vacuum annealing does not decompose the compound but enhances crystallization. To find the effect of annealing in vacuum, our film was annealed for $90 \mathrm{~min}$ at $400^{\circ} \mathrm{C}$. The $\ln (\sigma)$ vs $1 / T \times 10^{3}$ graph (figure 7) gives two different activation energies. The activation energy for the range $473 \mathrm{~K}$ to $500 \mathrm{~K}$ was obtained as $350 \mathrm{meV}$, which is slightly more than that obtained by Hiroyoshi and Kazuo (1984). For the temperature range $300 \mathrm{~K}$ to $473 \mathrm{~K}$, the activation energy was $150 \mathrm{meV}$, which is nearly the same as that obtained by Ueng and Hwang (1989). They have reported activation energy of $145 \mathrm{meV}$ for the 


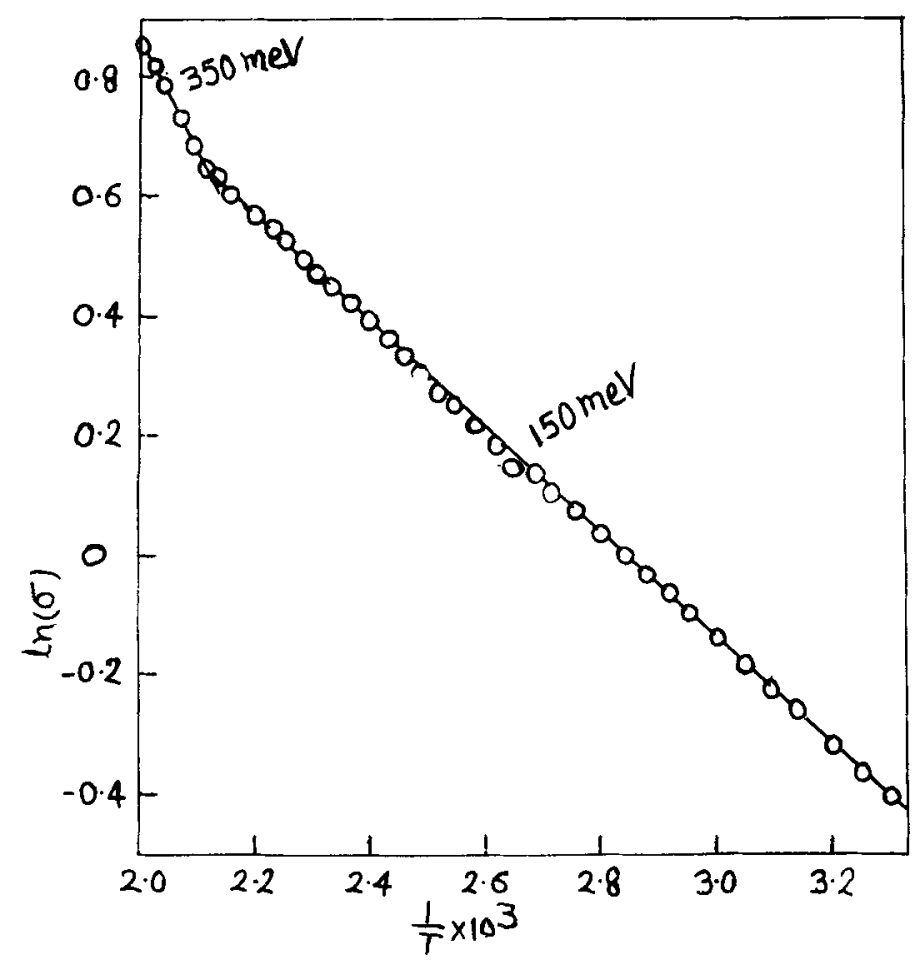

Figure 7. Arrhenius plot of conductivity of $\mathrm{CuInS}_{2}$ thin films after vacuum annealing for $1.5 \mathrm{~h}$ at $400^{\circ} \mathrm{C}$ (temperature range $300 \mathrm{~K}$ to $500 \mathrm{~K}$ ).

single crystal and attributed it to antisite defects of indium on copper sites $\left(\operatorname{In}_{\mathrm{Cu}}\right)$. Lange et al (1985) also have identified activation energy of $145 \mathrm{meV}$ from luminescence data and attributed it to the defect states of indium occupying copper site.

It has been suggested (Tell et al 1972; Migliorato et al 1975) that in $\mathrm{CuInS}_{2} / \mathrm{Se}_{2}$ $\left(\mathrm{Cu}-\mathrm{III}-\mathrm{VI}_{2}\right)$ ternary compound $\mathrm{Cu}$ and $\mathrm{In}$ vacancies act as acceptor levels. As $\mathrm{Cu}$ participates very weakly in covalent bond formation, $\mathrm{Cu}$ vacancies are more probable than In vacancies. For these vacancies in $\mathrm{CuInS}_{2}$, many workers (Lahlou and Masse 1981; Masse et al 1981; Masse 1984) have reported activation energies of the order of $45 \mathrm{meV}$ to $50 \mathrm{meV}$. An activation energy of $52 \mathrm{meV}$ obtained in our investigation is in fairly good agreement with this value and therefore may be attributed to $\mathrm{Cu}$ vacancy.

In addition to bulk conductivity, grain boundary conduction should also be taken into account while explaining the electrical behaviour of polycrystalline films at low temperatures. At low temperatures the effect of grain boundary is predominant when the grain size is small. The atoms at the grain boundary are disordered. There are a large number of defects due to incomplete atomic bondings. These form the trapping states and charge carriers are trapped and immobilized. The traps become electrically charged and give rise to potential barriers (Seto 1975). The conductivity temperature relation for such an effect was derived by Seto (1975). To verify whether the grain boundary effect is present, a graph of $\ln \left(\sigma T^{1 / 2}\right)$ vs $1 / T \times 10^{3}$ was plotted in the temperature range $150-300 \mathrm{~K}$ (figure 8 ). This plot is a straight line, which indicates the predominance of grain boundary effect in this temperature range. 


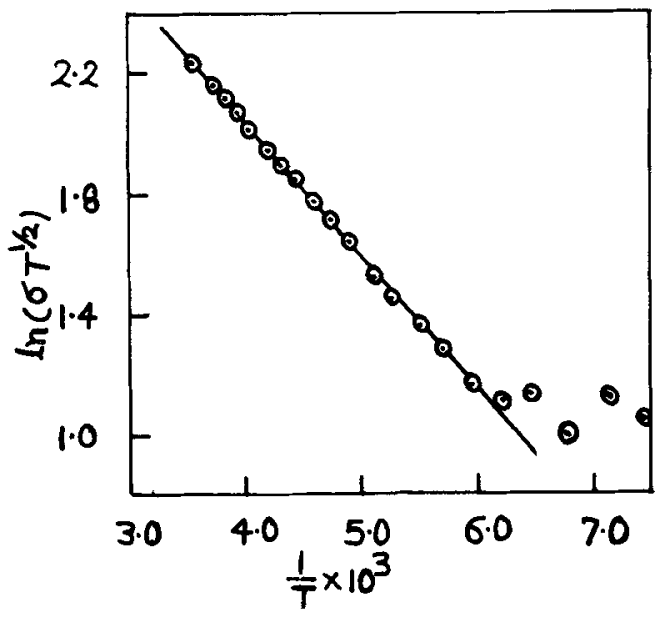

Figure 8. Plot of $\ln \left(\sigma T^{1 / 2}\right)$ vs inverse temperature showing grain boundary effect.

It appears that the observed activation energy ( $52 \mathrm{meV})$ may be due to the copper vacancies inside the grain or/and the formation of trapping states at the grain boundaries.

At very low temperature, all the trap states are filled and conduction occurs through the variable range hopping of the electrons in the localized states (Mathur et al 1983) at the Fermi level. Greaves (1973) derived an expression for the conductivity for variable range hopping (VRH) model applicable at low temperature as

$$
\sigma T^{1 / 2}=C \exp \left(-T_{0} / T\right)^{1 / 4}
$$

where $C$ and $T_{0}$ are constants and $T_{0}$ is related to the density $N\left(E_{\mathrm{F}}\right)$ of localized states by

$$
T_{0}=16 \alpha^{3} / k N\left(E_{\mathrm{F}}\right)
$$

where $\alpha^{-1}$ is a measure of the spatial extension of the wave function $\exp (-\alpha x)$ associated with the localized states. The ploi of $\ln \left(\sigma T^{1 / 2}\right)$ vs $T^{-1 / 4}$ for as-deposited film is indicated in figure 9 for the temperature range $90-125 \mathrm{~K}$. The slope of this plot gives the value of $T_{0}$, which comes out to be $9.872 \times 10^{3} \mathrm{~K}$. Taking (Ambegaokar et al 1972; Mott and Davis 1979; Dawar et al 1984) $\alpha^{-1}=10 \AA$, the value of $N\left(E_{\mathrm{F}}\right)$ was determined by using relation (4), which comes out to be $1.884 \times 10^{22} \mathrm{eV}^{-1} \mathrm{~cm}^{-3}$. Dawar et al (1984) reported the values of $T_{0}$ and $N\left(E_{\mathrm{F}}\right)$ for evaporated CuInTe $\mathrm{C}_{2}$ thin films. The values of $T_{0}$ reported by them are of the order of $10^{3}$ to $10^{2}$ and that of $N\left(E_{\mathrm{F}}\right)$ of the order of $10^{20}$ to $10^{23}$. Our values for $\mathrm{CuInS}_{2}$ thin films are of the same order of magnitude. The obtained value of $N\left(E_{\mathrm{F}}\right) \simeq 10^{22}$ is too large for a semiconductor. It appears that some correction to the assumed value of $\alpha^{-1}$ is necessary. The straight line nature of the plot indicates the validity of hopping conduction mechanism. with activation energy $8 \mathrm{meV}$. Similar mechanism was operative for flash evaporated (Sridevi and Reddy 1986) and spray pyrolytically deposited (Tembhurkar and Hirde 1992) $\mathrm{CuInSe}_{2}$ thin films, with low activation energy at the same temperature range. 


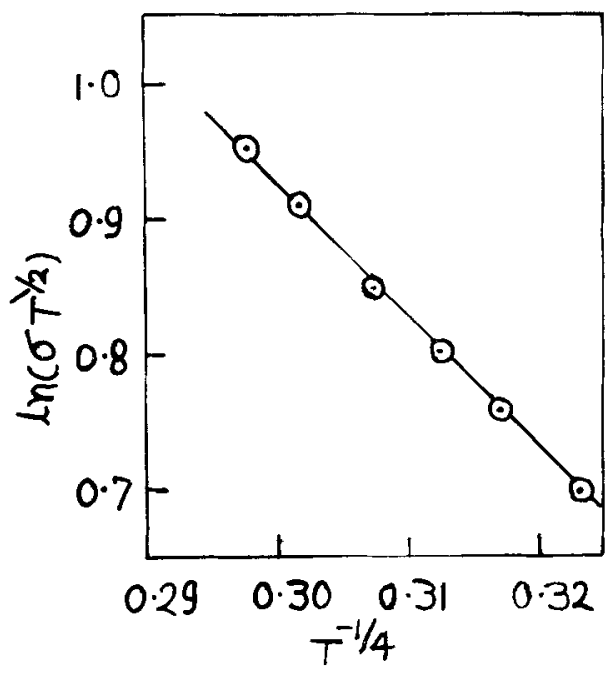

Figure 9. Plot of $\left(\sigma T^{12}\right)$ versus $T^{-14}$ showing hopping conduction in $\mathrm{CuInS}$, thin films.

\section{Hall mobility and carrier concentration at room temperature}

Hall coefficient at room temperature was determined by using Van der Pauw-Hall technique (Putley 1960). The Hall mobility and carrier concentration were calculated. Hall mobility at room temperature was found to be $6.15 \mathrm{~cm}^{2} \mathrm{~V}^{-1} \mathrm{~s}^{-1}$. This result is in fairly good agreement with that of Kazmerski et al (1975) who reported a value for Hall mobility of $8 \cdot 3 \mathrm{~cm}^{2} \mathrm{~V}^{-1} \mathrm{~s}^{-1}$. However, Tell et al (1972) reported a value of $15 \mathrm{~cm}^{2} \mathrm{~V}^{-1} \mathrm{~s}^{-1}$ for a single crystal.

The carrier concentration given by the relation

$$
p=\frac{1}{\left|e R_{H}\right|}
$$

comes to be $2.33 \times 10^{19} \mathrm{~cm}^{-3}$, which is in good agreement with the value obtained by Hiroyoshi and Kazuo (1984).

\section{Conclusion}

It was observed that $p$-type $\mathrm{CuInS}_{2}$ polycrystalline thin films can be deposited by spray pyrolysis. The structure is predominantly chalcopyrite with grain size of the order of $1 \mu \mathrm{m}$. The films have preferred orientation along 112 direction. Three direct allowed transition at $1.43,2.44$ and $2 \cdot 71 \mathrm{eV}$ were observed. The above room temperature investigation of resistivity reveals acceptor levels at $350 \mathrm{meV}$ and $150 \mathrm{meV}$. Below room temperature copper vacancies inside the grains or/and formation of trapping states at the grain boundaries play a major role in conduction. At very low temperature hopping conduction appears to be operative. 


\section{Acknowledgements}

The authors wish to thank Dr Pal, NBSS, and Mr S D Wachasunder, NEERI, Nagpur, for X-ray diffraction and transmission measurements respectively. One of the authors would like to thank the University Grants Commission, New Delhi, for award of a teacher fellowship.

\section{References}

Ambegaokar V, Halperin B I and Langner J S 1972 Phys. Rev. 342612

Dawar A L, Kumar A, Mall R P and Mathur P C 1984 Thin Solid Films 112107

Greaves G N 1973 J. Non-Cryst. Solids 11427

Grindle S P, Smith C W and Mittleman S D 1979 Appl. Phys. Lett. 3524

Hiroyoshi O and Kazuo M 1984 Jap. J. Appl. Phys. 8965

Hwang H L, Tu C C, Maa J S and Sun C Y 1980a Sol. Energy Mater. 2433

Hwang H L, Tseng B H, Sun C Y and Loferski J J 1980b Sol. Energy' Mater. 467

Hwang H L, Cheng C L, Liu L M, Lin Y-C and Sun C Y 1980c Thin Solid Films 6783

Kazmerski L L, Ayyagiri M S and Sanborn G A 1975 J. Appl. Phys. 464865

Kazmerski L L and Sanborn G A 1977 J. Appl. Phy's. 483178

Lahlou N and Masse G 1981 J. Appl. Phys. 52978

Lange P, Neff H, Fearheiley M L and Bachmann J 1985 J. Electronic Mater. 146

Masse G, Lahlou N and Buthi C 1981 J. Phys. Chem. Solids 42449

Masse G 1984 J. Phys. Chem. Solids 451091

Mathur P C, Sharma R P, Renuka S, Saxena P and Kotnala R K 1983 J. Appl. Phys. 543913

Meese J M, Manthuruthil J C and Locker R D 1975 Bull. Am. Phys. Soc. 20696

Migliorato P, Shay J L, Kasper H M and Wagner S 1975 J. Appl. Phys. 461777

Mott N F and Davis E S 1979 Electronic processes in non-crystalline material (Oxford: Clarendon Press)

Second edition

Neumann H, Horig W, Schumann B, Kuhn G, Savelev V and Lagzdonis J 1981 Thin Solid Films 79167

Pamplin B and Fiegelson R S 1979 Thin Solid Films 60141

Powder Diffraction File, Joint Committee on Powder Diffraction Standards, International Center for diffraction Data, Swarthmore, PA, Card 27-159

Putley H 1960 Hall effect and related phenomenon (London: Butterwords)

Rajaram P, Thangaraj R, Sharma A K, Raza A and Agnihotri O P 1983 Thin Solid Film 100111

Samann A N Y, Wasim S M, Hill A E, Armour D G and Tomlinson R D 1986 Phys. Status Solidi (a) 96317

Seto John Y W 1975 J. Appl. Phys. 465247

Shay J L and Wernick S H 1975 Ternary chalcopyrite semiconductors: growth, electronic properties and applications (Great Britain: Pergamon Press)

Sridevi D and Reddy K V 1986 Indian J. Pure and Appl. Phys. 24392

Tell B, Shay J L and Kasper H M 1972 J. Appl. Phys. 432469

Tell B and Thiel F A 1979 J. Appl. Phys. 505045

Tembhurkar Y D and Hirde J P 1992 Thin Solid Films 21565

Tuttle J R, Albin D, Goral J, Kennedy C and Nouff R 1988 Solar Cells 2467

Ueng H Y and Hwang H L 1989 J. Phys. Chem. Solids 501297 